\title{
Methodological Approaches to an Assessment of Stability of Universities
}

\author{
Alexander Pavlovich Latkin ${ }^{1}$ \\ Larisa Aleksandrovna Krokhmal2 \\ Yulia Anatolyevna Kovshun² \\ 1 Vladivostok state university of economy and service, Gogolya str., 41, Vladivostok, Primorsky Krai, 690000 \\ ${ }^{2}$ Far East state agricultural university, 675000, Amur Region, Blagoveshchensk, Politekhnicheskaya St., 86
}

\section{Doi:10.5901/mjss.2015.v6n6s3p173}

\section{Abstract}

In the article is offered author's approach to an assessment of the stability of the Russian system of the higher education. At its justification are considered requirements of known techniques of M.Shriberg (2002) \& Moreover, O. Saadatian, K.B. Dola \& O.M. Tahir (2011). As a basis for an assessment of the stability of the higher education is used the tensor methodology of actual design of the Russian School of Sciences of a sustainable development. Features of the development of the Russian universities were defined according to the known theory of steady changes of $B$. Clark and his triangular model of interaction between the market, the state and university community. As information base of research results of monitoring of the efficiency of higher education institutions of the Ministry of Education and Science of the Russian Federation were used. Because of researches by authors the conclusion that is drawn the state influence in integration interaction in Russia remains high. Mathematical dependence of stability of universities in Russia from the qualification of teachers, public financing, enterprise activity, the aspiration to develop high school science, and from a condition of infrastructure is established.

Keywords: stability, sustainable development, market, state, university community.

\section{Introduction}

In the definition of sustainable development, known as definition Brundtland, is said that the sustainable development satisfies requirements of the present, without threatening the ability of future generations, to satisfy own needs.

Basic approach to the problems solution of sustainable development is offered by the Russian School of Sciences (Kuznetsov): "The best way to an exit from global crisis and to keep our country and Earth for future generations - to form it the Person capable and realizing the ability to creativity for development of Life".

As a result, to education in the world increased the education imposes requirements promoting a sustainable development or in interests of sustainable development (Kuznetsov \& Bolshakov, 2013). universities.

However, most often there is crucial beyond the scope of researches, in our opinion, a question of stability of

The analysis of the literature devoted to a problem of a sustainable development of universities showed that researchers give attention to this problem insufficiently. Determination of stability of universities though contains a small amount of these works; however, often accents are displaced towards explanations of a role of universities in this process.

Most fully, in our opinion, meets requirements imposed by the stability of universities definition, which contains in Talluar - the declaration of a sustainable development signed by rectors of higher educational institutions of the whole world.

"Stability means that activity in college or university is environmentally friendly, socially fair and economically viable and that such activity will be continued for future generations" (http://www.ulsf.org/programs_talloires_history.html).

Though discussion concerning steady higher education is not finished yet, it is very important that in definition Talluar - declarations to universities requirement is imposed to economic viability that along with factors of social and ecological character provides development prospect.

Approaches to an assessment of stability of the higher education

Despite the widespread discussion of sustainability as well as continued interest in higher education, as an 
institution, contribute to sustainable development, work on the analysis methodologies for assessing the viability of the higher education system, not a great variety of (Antonioss \& Andy Van Den, 2015). Two works that are connected with researches strong and weaknesses of systems of estimates of stability are allocated in the higher education:

1) M. Shriberg (2002) Institutional tools of an assessment of stability in the sphere of the higher education: Strong, weaknesses, consequences for the theory and practice (Shriberg, 2002).

2) O. Saadatian, K.B. Dola \& O.M. Tahir (2011). Identification is strong and weaknesses of increase of stability in estimates of the educational organizations (Saadatian, Dola \& Tahir, 2011). At the heart of approach are put: the three-dimensional principle of Elkington (Elkington, 1997) and the principle of protection against subjectivity in estimates, which can be reached, according to Connolly (Connolly, Arkes \& Hammond, 2000), imposing requirements of complexity, novelty and popularity to techniques of estimates.

We propose to take into account the requirements of the proposed methods, but as a basis for assessing the sustainability of higher education use a tensor methodology for effective design of the Russian scientific school of sustainable development focused on the preservation of the system of nature-society-man. (Kuznetsov \& Bolshakov, 2002). The method is constructed on power conservation law (an energy stream) (J.L. Lagrange, J. Maxwell \& P.G. Kuznetsov), and his projection - the principle of "preservation of development of live systems" of Vernadsky and Bauer.

The main idea is that absence of the answer in one system of coordinates, allows passing into another where the answer exists, having changed statement of a question. Even the impasse is possible for the decision to transition to another system of measurement.

In our opinion, the offered methodology can be applied to any private questions of sustainable development as allows the considering stability of development as a projection of the general laws of nature in private systems of coordinates. It can be the certain state, the region, branch, corporation, university.

\section{Source of Information and Problem of Information Maintenance of Research}

As a source of information on variables, we chose to monitor results of the higher educational institutions efficiency in 2015 (following the results of 2014) (http://obrnadzor.gov.ru/ru/).

In a basis of researches, we relied on the management of the register of the educational organizations. According to the contents, it conforms to our requirements, which we created to determine necessary selection parameters: departmental accessory, type of the organization, its site and other.

The portal of Federal Service for Supervision in Education and Science (http://obrnadzor.gov.ru/ru/) provides the following data: the card of the licensed educational institutions of the Russian Federation; summary register of licenses for implementation of educational activity (http://obrnadzor.gov.ru/ru/); the register of the accredited educational institutions and the scientific organizations (http://obrnadzor.gov.ru/ru/).

The card of higher education institutions (http://obrnadzor.gov.ru/ru/) gives the chance to construct the list of the educational organizations for the following filters: federal district, region, settlement, name, higher education institution, form of ownership, accreditation, and specialty. In total 4640 institutions of higher learning are presented in the map, from them head state universities 2200, non-state head institutions of higher education - 548 .

As the initial list of higher education institutions, we took the data placed on a portal of monitoring of employment of graduates (http://graduate.edu.ru). Here it is possible to see the general register of higher education institutions, to make the list on such filters as a field of activity, qualification, the region, the federal district, the integrated group of specialties. However, use of a portal as data source is limited to the following factors:

- Only two types of data - the employment (including a share of the employed graduates, specific weight of individual entrepreneurs and threshold value of jobs for the region) and the average sum of payments (including their middle age besides the sum of payments to graduates) are presented;

- The number of higher education institutions in two registers differs: in the register of employment of 820 educational organizations, and in the register of the sums of payments - 817;

- There is no opportunity to copy registers from a portal for further processing and carrying out analytics.

Thus, our selection consisted of 817 higher educational institutions of Russia, on each higher education institution in the selection, seven indicators are brought, and the regression model is created.

\section{Problem Definition}

Definition Talluar - the declaration of a sustainable development signed by rectors of higher educational institutions of the whole world (http://www.ulsf.org/programs_talloires_history.html) is the cornerstone of researches. 
Possibly to consider features of development of universities, relying on the known theory of steady changes of B. Clark (Clark, 2011) and his triangular model of integration interaction between the market, the state and university community (Clark, 2011).

At the creation of hypotheses we relied on the tensor methodology of actual design of the Russian School of Sciences of a sustainable development of P. G. Kuznetsov (Kuznetsov \& Bolshakov, 2002) focused on preservation of development in system the nature-society-person. The logic of research is constructed in a situation that the essence even the most difficult system can be described the equation. The most difficult, in this case, is a search for such equation. The process of search is represented as creative, informal and depends on the idea of the researcher (Kron, 1978).

\subsection{Hypothesis 1}

The result of sustainable development is defined by the reaction of the environment (market) to the quality of training of graduates of the University. The reaction of the environment can be measured by the size of a salary of the graduates employed within the first year.

\subsection{Hypothesis 2}

The university steadily develops if in response to calls from the state and the market it is capable of changing the directions of the activity, increasing the volume of resources and quality of the rendered services for ensuring the economic viability guaranteeing to university community social and ecological wellbeing.

\subsection{Economic viability}

Economic sustainability can be measured by the volume of the financial resources attracted from all sources, including public financing and non-budgetary sources. For these purposes we used indicators:

- A share of income of higher education institution gained from budgets of different level on educational and scientific activity;

- The income of higher education institution from the budget on 1 trained;

- The income of higher education institution on only 1 trained;

- Share of the off-budget income of Research work in the total amount of the income of Research work;

- Share of the income from SDA in the total amount of the income;

- Income from science is counting on 1 CPD.

\subsection{Social wellbeing}

Social wellbeing of universities can be measured:

- The size of the salary falls on one teacher;

- The relation of an average wage of CPD to an average wage in the region (in the Russian Federation);

- The area of educational and laboratory rooms (comfortable conditions for work and training) counting on 1 trained.

\subsection{Ecological wellbeing}

Ecological wellbeing - one of the indicators, most difficult for an assessment, especially as in the Russian practice such measurements do not meet. We argued based on those indicators which efficiency monitoring, and because of researches of references on studying of the external and internal environment of the enterprises and the organizations contains. Therefore, using data from monitoring of efficiency, we chose indicators that are connected with ecological safety. It should be noted that the choice was difficult to be made, as the idea of monitoring does not answer conditions of a sustainable development. The first of indicators that, in our opinion, can be used for an assessment of ecological wellbeing - the particular weight of the cars used by universities in activity that age does not exceed five years. The logic selection from our reasoning's is as follows: the use of new cars does not worsen ecological wellbeing whereas old cars pollute environment, worsen environment. Besides, the aspiration of universities to acquire new equipment testifies that universities promote studying of the new technologies demanded by the market. However, the environment can be 
considered not only as natural but also as an external environment of higher education institution. Then critical are two more indicators:

- Average level of a salary of graduates as reaction of environment to results of activity of higher education institution;

- Contracts with the enterprises (number of the enterprises - bases of practice with which the contract of training of specialists) as the reaction of the environment to the activity of higher education institution is signed.

We decided to measure the internal environment of university by means of an indicator - a share of scientific and pedagogical workers with academic degrees and ranks, claiming that this percentage is higher, the internal environment of higher education institution has the best characteristics.

A check showed that the set conditions and methodological requirements are confirmed by all set of indicators that we chose for the analysis. We placed these indicators on a triangular design, based on Clark's theory about integration interaction, and constructed model of integration interaction "the state - market-university community" with an initial set of indicators of a sustainable development (figure 1).

Finally, estimating influence of the chosen factors, we assume that it is possible to establish:

1. Whether these factors influence stability of universities;

2. What extent of influence of each of factors on stability;

3. What of participants of integration relationship of B. Clark manages to establish "the rules of the game";

4. What model of integration relationship;

5. It possible to operate the stability of universities.

The dependent variable in our model was chosen wages of college graduates; we appreciate it as a qualitative characteristic of the performance of institutions of higher education. The higher the salaries of graduates, the better "product" released the university, and the more the market is willing to pay for this product. Also, we talked earlier about the fact that, using the quantitative characteristics of the wages of college graduates, one can measure the reaction of the environment on the activity of the university.

Source: authors make it

It is necessary to notice that the average salary counting on one Research and teaching staff (CPD) and the relation of an average wage of CPD to an average wage in the region (across the Russian Federation) is carried by us to factors of the state influence not casually. The action of the Decree of the Russian President on May 7, 2012, No. 597 assumes additional public financing on the increase of compensation for this category of workers (Latkin \& Krokhmal, 2014).

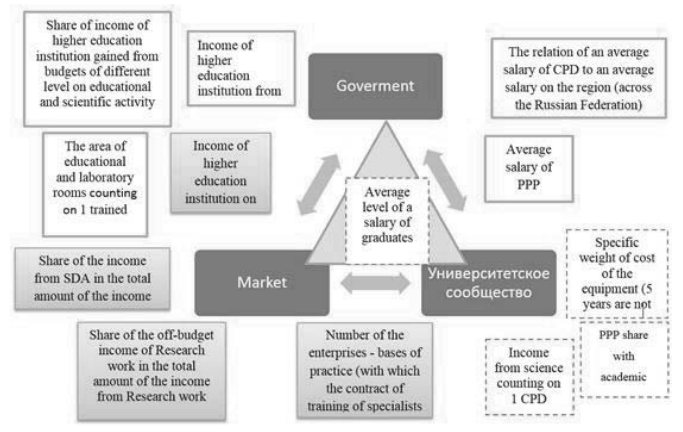

Figure 1 - Model of integration interaction the state - market-university community with an initial set of indicators of sustainable development

Usually in the economy at the publication of results of researches, the "good", statistically significant results confirming a hypothesis get out. In our opinion, the "bad" results that are not coinciding with the made hypothesis can be a source of additional conclusions.

Following the results of the analysis of a correlation matrix indicators with correlation higher than 0,6 were excluded. Consequently, there were nine indicators, on three in each group. At the creation of regression model, we used an option of grebnevy regression. The following characteristics of the multiple regression models (Table 1) are received as a result. 
Table 1 - Of the Characteristic of multiple regression models

\begin{tabular}{|c|c|c|c|c|c|c|c|}
\hline & & \multicolumn{6}{|c|}{$\begin{array}{l}\text { Ridge Regression Summary for Dependent Variable: Payments } \\
\text { to graduates(dataHE_5) } \\
\text { l=,10000 } R=, 59531626 R^{2}=, 35440145 \text { Adjusted } R^{2}=, 34863718 \\
F(6,672)=61,482 p<0,0000 \text { Std.Error of estimate: } 10,204\end{array}$} \\
\hline & & Beta & Std.Err. & $B$ & Std.Err. & $t(672)$ & p-level \\
\hline Intercept & & & & 16,24846 & 2,177164 & 7,46313 & 0,000000 \\
\hline Average salary of CPD & $\mathrm{X}_{3}$ & 0,461969 & 0,032733 & 0,22617 & 0,016025 & 14,11305 & 0,000000 \\
\hline Square at 1 trained & $\mathrm{X}_{2}$ & 0,109169 & 0,031212 & 0,03923 & 0,011216 & 3,49765 & 0,000500 \\
\hline Income from the budget on 1 trained & $X_{5}$ & 0,134317 & 0,037483 & 0,00816 & 0,002276 & 3,58346 & 0,000364 \\
\hline Share of the income from professors teaching activities SDA & $X_{9}$ & 0,121018 & 0,035760 & 0,04948 & 0,014622 & 3,38417 & 0,000755 \\
\hline Income from science on $1 \mathrm{CPD}$ & $\mathrm{X}_{12}$ & 0,074320 & 0,032744 & 0,00266 & 0,001174 & 2,26969 & 0,023542 \\
\hline CPD share with academic degrees & $\mathrm{X}_{10}$ & $-0,075689$ & 0,033593 & $-0,06079$ & 0,026979 & $-2,25315$ & 0,024571 \\
\hline
\end{tabular}

The value of F-statistics $=61,482$ at a significance value $p<0,0000$, i.e. the hypothesis of lack of linear communication deviates and admits their statistical importance and reliability. Communication in linear model weak, the coefficient of determination is a variation of factors explains equal 0,358 , i.e. the result variation only for $35 \%$. Darbin-Watson's ( $D W=1,647)$ statistics shows that autocorrelation of the remains is absent. So, for model of grebnevy regression the dependent variable "average level of a salary of graduates" is presented as:

$Y=16,24846+0,03923 X_{2}+0,22617 X_{3}+0,00816 X_{5}+0,04948 X_{9}--0,060709 X_{10}+0,00266 X_{12}$

Of the six explanatory variables, three belong to the group "the state» (X2-area teaching and laboratory space per 1 student, X3-average wages per scientific and teaching staff, X5-revenues of the university from the budget for 1 student) one - to the "market» (X9-share of profits from the SDA in the total revenues), and 2 - to "academic oligarchy» (X10-share of academic staff with academic degrees and titles, X12-revenues from science based on 1 CPD ).

Because of the conducted researches, we constructed integration and interaction model of the state - marketuniversity community with a set of the indicators influencing a sustainable development of universities (figure 2) and drew some conclusions.

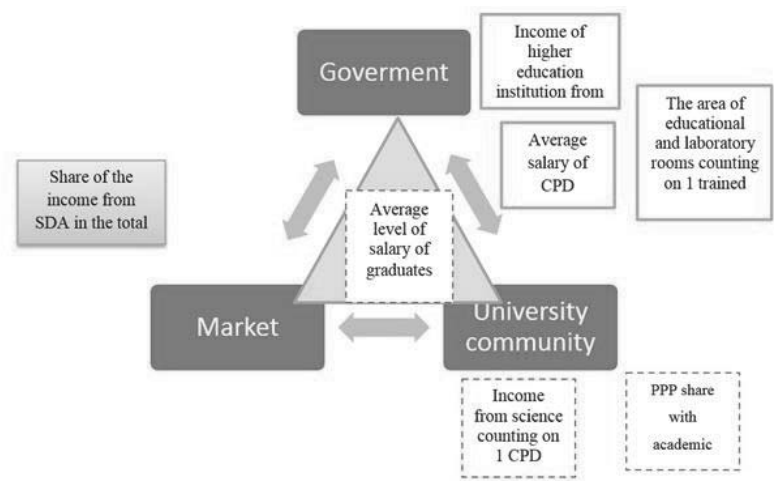

Figure 2 - Model of integration interaction the state - market-university community with a set of the indicators influencing a sustainable development of universities

\section{Conclusion}

Stability of universities in Russia depends on qualification of teachers, the volume of the state financial security, enterprise activity of universities, the aspiration to develop high school science, and from a condition of infrastructure.

The state influence in integration interaction between the market, university community in Russia remains unfairly high (Krokhmal \& Akhapkina, 2015). Influence of the market remains to the lowest, and the University community directs the efforts more on the regulation of the internal environment connected with ensuring the quality of educational services. As a positive result, it is necessary to recognize aspiration of universities to business. 
Monitoring of efficiency of higher education institutions has to contain the set of indicators and especially built-in tools allowing defining the stability of higher education institutions at the time of carrying out monitoring in Russia. At the first stage of development, it is possible to use the model of sustainable development created by results of research. It will allow making quick decisions on change of the directions of development of universities.

The revealed directions stimulation of stability is possible to bring universities to a trajectory of sustainable development. The offered model has to be corrected eventually; it has to be added to other factors created by development results.

\section{References}

Antonios, Maragakis \& Andy Van Den, Dobbelsteen (2015) Sustainability in Higher Education: Analysis and Selection of Assessment Systems. Journal of Sustainable Development; Vol. 8, No. 3: 1-9.

Elkington, J. (1997). Cannibals with Forks: The Triple Bottom Line of 21st Century Business. Capstone Publishing, Oxford.

Clark, B.R. (2011) Maintenance of changes in universities. Continuity a case stage and concepts the [Text] / translation from English by E. Stepkina; National research University "Higher School of Economics". M.: Prod. House of Higher School of Economics. pp. 312.

Clark, B.R. (2011) Sistema of the higher education: the academic organization in the cross-national prospect of the [Text] / lane from English A. Smirnov; National research University "Higher School of Economics". M.: Prod. House of Higher School of Economics. pp. 360.

Connolly, T., Arkes, H.R., \& Hammond, K.R. (2000). Judgment and decision making: an interdisciplinary reader (Vol. 1). Cambridge: Cambridge University Press.

Kron, G. (1978) Tensor analysis of networks: translation from English; under edition of Kuzina L.T. and Kuznetsov P.G. M: Soviet radio, 1978. pp. 720.

Krokhmal, L.A. \& Akhapkina, E.N. (2015) To a problem of development of agrarian education in Russia. WORLD (Modernization. Innovations. Development). Release No. 2-1 (22)/volume 6 / 2015. pp. 129-136.

Kuznetsov, O.L. \& Bolshakov, B.E. (2002) Sustainable development: scientific bases of design in system the nature-society-person the Textbook XXI centuries. Spb-Moscow-Dubna, "Gumanistika".

Kuznetsov, O.L. \& Bolshakov, B.E. (2013) World Sustainable Development - M .: Natural Sciences. pp. 221.

Latkin, A.P. \& Krokhmal, L.A. (2014) Territorial aspect of innovative approach in the organization of financing of higher education institutions. Economy and management of control systems. No. 4.2(14). pp. 267-275.

Saadatian, O., Dola, K.B. \& Tahir, O.M. (2011). Identifying Strengths and Weakness of Sustainable Higher Educational Assessment Approaches, International Journal of Business and Social Science, 2(3). pp. 137-146.

Shriberg, M. (2002). Institutional assessment tools for sustainability in higher education: strengths, weaknesses, and implications for practice and theory. Higher Education Policy, 15(2). pp. 153-167.

http://obrnadzor.gov.ru/rul

http://graduate.edu.ru/

http://www.ulsf.org/programs_talloires_history.html 